Journal of Physical Science, Vol. 28(2), 71-84, 2017

\title{
Influences of the Coupling Agent and Various Compatibilisers on Properties of Recycled High Density Polyethylene/Ethylene Vinyl Acetate/Taro Powder (Colocasia esculenta) Biocomposites
}

\author{
Fatimah Abd. Rajak Hamim, ${ }^{1}$ Supri Abdul Ghani2 ${ }^{*}$ and Firuz Zainuddin ${ }^{1}$ \\ ${ }^{1}$ School of Materials Engineering, Universiti Malaysia Perlis (UniMAP), \\ Kompleks Taman Muhibah, Jejawi 2, 02600 Arau, Perlis, Malaysia \\ ${ }^{2}$ Faculty of Engineering Technology, Universiti Malaysia Perlis (UniMAP), \\ Sungai Chuchuh, 02100 Padang Besar, Perlis, Malaysia \\ *Corresponding author: supri@unimap.edu.my
}

Published online: 15 August 2017

To cite this article: Abd. Rajak Hamim, F., Abdul Ghani, S. \& Zainuddin, F. (2017). Influences of the coupling agent and various compatibilisers on properties of recycled high density polyethylene/ethylene vinyl acetate/taro powder (Colocasia esculenta) biocomposites. J. Phys. Sci., 28(2), 71-84, https://doi.org/10.21315/jps2017.28.2.5

To link to this article: https://doi.org/10.21315/jps2017.28.2.5

\begin{abstract}
The recycled high density polyethylene/ethylene vinyl acetate (RHDPE/ EVA) blend was prepared by using Brabender Plasticoder mixer. Taro powder (TP) filler was added to produce RHDPE/EVA/TP composite. The effect of TP filler and different modifications approached: by treatment of TP filler with methyl methacrylate (MMA); by addition of commercial compatibiliser of polyethylene grafted maleic anhydride (PE-g$M A H)$; and by addition of hybrid compatibiliser of caprolactam-maleic anhydride (CLMAH) were studied. Tensile properties, swelling behaviour, morphology, and thermal properties were also investigated. Findings indicated that the addition of TP filler led to the reduction in tensile strength and elongation at break while showing increment in modulus of elasticity. Upon modifications, the tensile strength and modulus of elasticity increased while the elongation at break decreased slightly. The composites exhibited an increased chemical uptake resulting in increased percentage mass swell once TP filler was added and after modification of the composites. The usage of compatibiliser and treatment of filler enhanced interfacial adhesion of matrix and filler with improvement in dispersion of filler as evidenced by scanning electron microscopy (SEM).
\end{abstract}

Keywords: Recycled high density polyethylene, ethylene vinyl acetate, taro powder, methyl methacrylate, polyethylene grafted maleic anhydride.

(C) Penerbit Universiti Sains Malaysia, 2017. This work is licensed under the terms of the Creative Commons Attribution (CC BY) (http://creativecommons.org/licenses/by/4.0/). 


\section{INTRODUCTION}

Polymer composites have been extensively used for numerous years and their production for the market is continuously growing. The use of a polymer and filler allows to achieve several advantages and, in particular, combination of the basic properties from both matrix and filler. ${ }^{1}$ Matrix is a constituent that is continuous with the main purpose to enclose and bind the reinforcement, while reinforcement phase functions as primary load-bearing constituent in the composites. ${ }^{2}$ Polymer matrix composites are the commonly used composites because of their high strength, low cost, and simple manufacturing techniques. ${ }^{3}$ Thermoplastic matrix composites processing temperatures are higher than those thermosets but they have better toughness and impact resistance with the parts can be remolded, made and joined by heating. ${ }^{4}$

Natural filler-reinforced polymer composites have received extensive attention and are being studied as a valuable alternative for reinforcement in composites industry due to their specific properties such as low cost, biodegradability, easy availability and low density. ${ }^{5}$ The natural filler's exact properties are equivalent to synthetic fillers that are basically used as reinforcement in composites. Moreover, natural fibres are also nonabrasive and apply less wear in processing compared to inorganic fibers. ${ }^{6}$

Taro (Colocasia esculenta) is a wetland herbaceous perennial, and fast emerging amphibious plant which has become a problem due to its thick vegetation in Malaysia and other countries. The thick vegetation causes harm to water bodies in which they colonise and their abundant bushes shelter poisonous creatures and insect pests, and become breeding grounds for mosquitoes and other illness course. ${ }^{7}$ The high content of starch in taro, $25 \%-30 \%$, is the most important reason it can be used in industry because this feature contributes to the ease of digestibility of taro. Taro can be applied as fillers or modifiers for plastics when their starch is used in the production of plastic which can help to accelerate the biodegradability of the parent polymer. ${ }^{8}$ However, large difference in surface polarity between hydrophilic filler and hydrophobic matrix causes poor interfacial adhesion and thus leads to poor mechanical properties of final materials.

Certain surface modifications of natural fillers are usually needed to improve the interfacial interaction between matrix and filler. Chemical treatments basically provide active functional groups that can form linkage or bonding within the composites and in some cases changing the filler composition to improve interaction. ${ }^{9,10}$ Besides, the use of compatibiliser can become effective to enhance the coupling and the interaction between natural filler and polymer matrix. ${ }^{11}$ 
Compatibilisers will modify polymer interfaces by increasing the adhesion at phase boundaries, decreasing the interfacial tension in the melt while lessening phase separation in solid state and stabilising the dispersed phase. ${ }^{12}$ Khanam and AlMaadeed studied the effect of maleic anhydride as compatibiliser on ternary recycled polymer blend reinforced with date palm fibre. ${ }^{13}$ From the report, they suggested that addition of $1 \%$ of maleic anhydride into the polymer blend improved the mechanical properties, thermal stability, and water absorption of the recycled polymer blend matrix.

In this research, TP filler was chemically treated using coupling agent like methyl methacrylate to improve the compatibility with the RHDPE/EVA matrix. The RHDPE/EVA/TP composites were compatibilised by using commercial compatibiliser of PE-g-MAH and hybrid compatibiliser of CL-MAH. Caprolactam was grafted in-situ with maleic anhydride monomers through the Brabender mixer, and the grafted compatibiliser was then compounded with the composites. The content of the TP filler selected was $25 \mathrm{phr}$ to reduce the cost of the composites. The objectives of the study were to study the effect of TP filler on the RHDPE/ EVA blend and composite modification on tensile properties, swelling behaviour, and morphology of tensile fractured surface of RHDPE/EVA, RHDPE/EVA/TP, RHDPE/EVA/TP ${ }_{\mathrm{MMA}}$, RHDPE/EVA/TP/PE-g-MAH, and RHDPE/EVA/TP/CLMAH composites.

\section{EXPERIMENTAL}

\subsection{Materials}

The thermoplastic used in this work were RHDPE with melt flow index of $0.7 \mathrm{~g} / 10 \mathrm{~min}\left(190^{\circ} \mathrm{C}\right)$ and density of $0.97 \mathrm{~g} / \mathrm{cm}^{3}$ and EVA with $18.1 \mathrm{wt} \%$ of vinyl acetate (VA), melt index of $2.5 \mathrm{~g} / 10 \mathrm{~min}\left(80^{\circ} \mathrm{C}, 2.16 \mathrm{~kg}\right)$, and density of $0.93 \mathrm{~g} / \mathrm{cm}^{3}$ which both were provided by A. R. Alatan Sdn. Bhd., Kedah, Malaysia. The TP filler used as reinforcing filler was obtained from local village in Sabak Bernam, Selangor. The basic ingredients of TP were shown in Table 1. MMA with molecular weight of $100.12 \mathrm{~g} / \mathrm{mol}$, PE-g-MAH with density of $0.925 \mathrm{~g} / \mathrm{cm}^{3}$, and caprolactam with with molecular weight of $113.16 \mathrm{~g} / \mathrm{mol}$ were supplied by Zarm Scientific \& Supplier Sdn. Bhd., Penang, Malaysia. Besides that, maleic anhydride with molecular weight of $98.06 \mathrm{~g} / \mathrm{mol}$, dichloromethane with molecular weight of $84.93 \mathrm{~g} / \mathrm{mol}$, and dibenzoyl peroxide with $75 \%$ water remainder with molecular weight of $242.23 \mathrm{~g} / \mathrm{mol}$ were also used in the research. All of the latter chemicals were provided by A. R. Alatan Sdn. Bhd., Kedah Darul Aman, Malaysia. 
Table 1: Ingredient of TP filler was analysed by Laboratory Department of DXN Holdings Bhd., Jitra, Kedah.

\begin{tabular}{ll}
\hline Content & Quantity \\
\hline Calories & $274 \mathrm{Kcal}$ \\
Carbohydrate & $52.6 \%$ \\
Fat & $1.2 \%$ \\
Protein & $13.1 \%$ \\
\hline
\end{tabular}

\subsection{Filler and Compatibiliser Preparation}

In preparing the TP filler, the stems from taro plants were cut, washed with tap water, dried, and grinded to powder by using grinder machine. Taro powder filler was then sieved to obtain TP filler with average sizes of $75 \mu \mathrm{m}$. TP filler with average sizes of $75 \mu \mathrm{m}$ was dried in vacuum oven at $80^{\circ} \mathrm{C}$ for $1 \mathrm{~h}$. The chemical treatment of TP filler was prepared by mixing $6 \mathrm{wt} \%$ of MMA solution with ethanol which acts as a solvent. TP filler was added into the mixture and mechanically stirred by using mechanical stirrer for $4 \mathrm{~h}$ at room temperature until homogenously mixed. The solution was then heated at $80^{\circ} \mathrm{C}$ for $15 \mathrm{~min}$ to permit MMA to completely dissolve in the solution, and kept at room temperature for $24 \mathrm{~h}$ until two layers were formed. The upper layer was poured out while the precipitate of treated TP filler with MMA was filtered and permitted to dry in oven at $40^{\circ} \mathrm{C}$ for $24 \mathrm{~h}$ to completely remove the ethanol residue. Meanwhile, hybrid compatibiliser CL-MAH was prepared by mixing $3 \mathrm{phr}$ of CL and MAH, respectively. The mixing was mixed together in the process of composites' compounding by melt-blend technique.

\subsection{Composite Preparation}

For composites preparation, the compounding process of the composites was conducted by melt blending in Brabender Plasticoder internal mixer. The RHDPE was first put into the internal mixer at $160^{\circ} \mathrm{C}$ with rotation speed of $50 \mathrm{rpm}$ for 2 min, followed by addition of EVA which was left to be mixed with RHDPE until homogenous for another $2 \mathrm{~min}$. TP filler was then added into the mixer and the blending last after $6 \mathrm{phr}$ of compatibiliser mounted into the mixer. Dibenzoyl peroxide (DBP) was added as initiator before the compatibiliser to prepared free radicals for the chain. Later, the completely compounded composites were removed from the internal mixer and pressed into round pieces before put into the mold for compression molding. The process was repeated for the compounding of RHDPE/ EVA/TP $\mathrm{TMA}_{\text {MM }}$ composites by changing the TP filler with treated $\mathrm{TP}_{\mathrm{MMA}}$ filler. Table 2 shows the formulation used in this research. 
Table 2: Formulation of RHDPE/EVA, RHDPE/EVA/TP, RHDPE/EVA/TP ${ }_{\text {MMA }}$, RHDPE/ EVA/TP/PE-g-MAH and RHDPE/EVA/TP/CL-MAH composites.

\begin{tabular}{lcccccc}
\hline Composite code & $\begin{array}{c}\text { RHDPE } \\
\text { (phr) }\end{array}$ & $\begin{array}{c}\text { EVA } \\
\text { (phr) }\end{array}$ & $\begin{array}{c}\text { TP } \\
\text { (phr) }\end{array}$ & $\begin{array}{c}\text { TPMMA } \\
\text { (phr) }\end{array}$ & $\begin{array}{c}\text { PE-g- } \\
\text { MAH } \\
\text { (phr })\end{array}$ & $\begin{array}{c}\text { CL-MAH } \\
\text { (phr) }\end{array}$ \\
\hline RHDPE/EVA & 80 & 20 & 25 & - & - & - \\
RHDPE/EVA/TP & 80 & 20 & 25 & - & - & - \\
RHDPE/EVA/TPMMA & 80 & 20 & - & 25 & - & - \\
RHDPE/EVA/TP/PE-g-MAH & 80 & 20 & 25 & - & 6 & - \\
RHDPE/EVA/TP/CL-MAH & 80 & 20 & 25 & - & - & 6 \\
\hline
\end{tabular}

\subsection{Compression Molding}

The hydraulic hot press was used to produce the composites in plate form. Both top and bottom platen of the machine was set at temperature $160^{\circ} \mathrm{C}$. Empty mold was heated for $5 \mathrm{~min}$ before used. Then, the compounding pieces of the composites were placed into the center of the mold and compressed partially for $8 \mathrm{~min}$ for preheating. As soon as the composites started to soften, the compounding composites were completely compressed for 6 min under pressure of $15 \mathrm{MPa}$. After compression, the composites which already turned into plate form were left to cool for extra 4 min.

\subsection{Tensile Test}

The tensile tests were carried out by using the Universal Testing Machine Instron 5569 according to ASTM D 638. The dumbbell shape specimens used for the test had a cross section of $6.5 \times 2 \mathrm{~mm}^{2}$ each. The test was completed at conditioned ambient temperature $(25 \pm 3)^{\circ} \mathrm{C}$ and relative humidity $(30 \pm 2) \%$ with crosshead speed of $30 \mathrm{~mm} / \mathrm{min}$. A regular of five samples was used for each formulation. The tensile strength, elongation at break, and modulus of elasticity of each formulation were achieved from the test.

\subsection{Swelling Behaviour Test}

The swelling behaviour test was carried out in general accordance with ISO 1817. Samples with dimension of $20 \mathrm{~mm} \times 10 \mathrm{~mm} \times 2 \mathrm{~mm}$ were used for each composites composition. The samples were fully immersed into beakers having dichloromethane for $46 \mathrm{~h}$. After the immersion period, the samples were taken out and wiped with tissue paper before weighed by using an analytical balance with $0.1 \mathrm{mg}$ resolution. The degree of swelling was calculated as follows: 
(\%) Mass Swell $=\frac{\left(\mathrm{W}_{\mathrm{s}}-\mathrm{W}_{\mathrm{o}}\right) \times 100}{\mathrm{~W}_{\mathrm{o}}}$

where $\mathrm{W}_{\mathrm{o}}$ is the initial weight of sample, and $\mathrm{W}_{\mathrm{s}}$ is the weight of the swollen sample after immersion.

\subsection{Scanning Electron Microscopy (SEM)}

The tensile fracture surfaces of the composites were analysed with a JEOL JSM 6460LA SEM. The samples were mounted on aluminium stubs before the testing to undergo sputtering coating of thin platinum layer of $20 \mathrm{~nm}$ on the samples surfaces to evade electrostatic charge.

\section{RESULTS AND DISCUSSION}

\subsection{Tensile Properties}

Figure 1 shows the tensile strength of RHDPE/EVA, RHDPE/EVA/TP, RHDPE/ EVA/TP ${ }_{\text {MMA }}$, RHDPE/EVA/TP/PE-g-MAH, and RHDPE/EVA/TP/CL-MAH composites with 25 phr of TP filler loading. From the figure, unfilled composites of RHDPE/EVA displayed the highest tensile strength compared to the TP filled composites. On the other hand, for the TP filled composites, RHDPE/EVA/TP/ CL-MAH had the highest tensile strength followed by RHDPE/EVA/TP/PE-g$\mathrm{MAH}, \mathrm{RHDPE} / \mathrm{EVA} / \mathrm{TP}_{\mathrm{MMA}}$, and RHDPE/EVA/TP composites. All composites associated with compatibiliser and coupling agent exhibited higher tensile strength than the uncompatibilised composites. These results show that the incorporation of compatibiliser and coupling agent had enhanced the compatibility between RHDPE/EVA matrix and the TP filler.

The addition of TP filler into those composites had resulted in decreasing value of tensile strength. This can be explained by the incompatibility between filler and matrix. The incompatibility reduced the ability of good stress transfer within the composites because the presence of voids initiated cracks when stress was applied during tensile test. However, the RHDPE/EVA/TP composite shows improvement upon filler treatment and addition of compatibilisers. Treatment of TP with MMA increased the bonding between TP filler and RHDPE/EVA matrix by the presence of carboxyl groups in MMA which bond with hydroxyl groups of TP filler, resulting in formation of bridge that provided better stress transfer within the composites. 


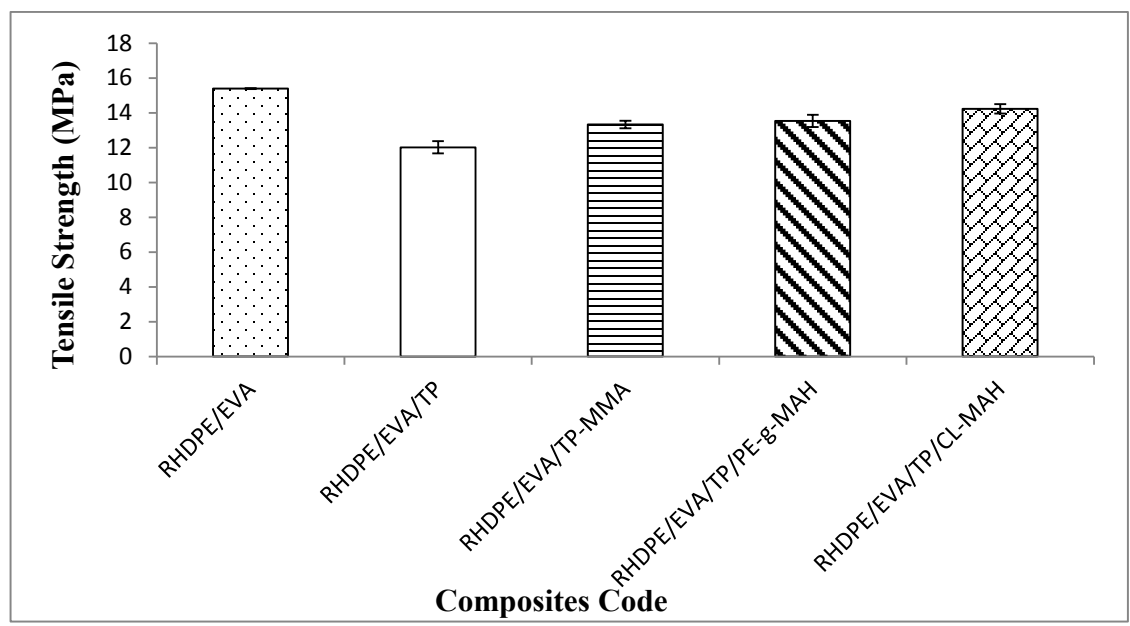

Figure 1: Tensile strength of RHDPE/EVA, RHDPE/EVA/TP, RHDPE/EVA/TP MMA $_{\text {, }}$ RHDPE/EVA/TP/PE-g-MAH, and RHDPE/EVA/TP/CL-MAH composites.

Meanwhile, the addition of compatibiliser of PE-g-MAH and CL-MAH, respectively, into the composites enhanced the tensile strength of RHDPE/EVA/ TP/PE-g-MAH and RHDPE/EVA/TP/CL-MAH composites. The existence of maleic anhydride resulted in the formation of interaction between anhydride groups of MAH to hydroxyl groups of TP filler in the amorphous region of cellulose structure. ${ }^{15}$ The bonding caused removal of hydroxyl groups from TP filler, thus reduced the hydrophilicity of the composite and provided efficient interlocking of TP filler into RHDPE/EVA matrix. The polyethylene in PE-g-MAH will form C-C bond to RHDPE or ethylene in EVA long chain while CL in CL-MAH will bond to the vinyl acetate of EVA, respectively. The RHDPE/EVA/TP/CL-MAH shows higher tensile strength value than RHDPE/EVA/TP/PE-g-MAH composites due to the presence of benzyl ring in caprolactam which added more strength to the long chain of composites compared to mere ethylene groups in RHDPE/EVA/TP/PE-gMAH composites.

Figure 2 shows the elongation at break of RHDPE/EVA, RHDPE/EVA/TP,

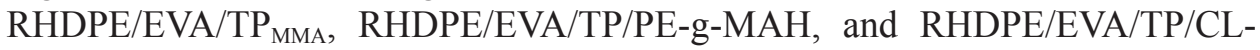
MAH composites. From the figure, it can be distinguished that RHDPE/EVA blend had the highest elongation at break value and the addition of TP decreased the elongation at break of the rest of the composites. The treated and compatibilised composites exhibited lower tensile strength compared to the RHDPE/EVA/TP composites. 


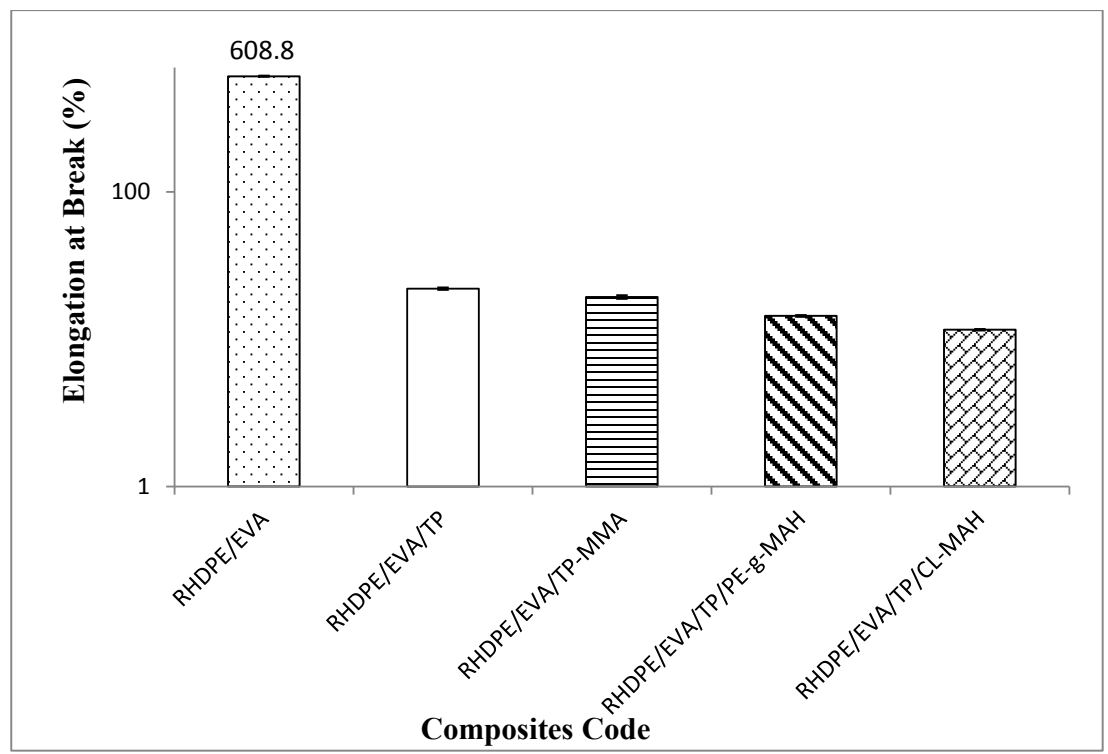

Figure 2: Elongation at break of RHDPE/EVA, RHDPE/EVA/TP, RHDPE/EVA/ $\mathrm{TP}_{\mathrm{MMA}}$, RHDPE/EVA/TP/PE-g-MAH, and RHDPE/EVA/TP/CL-MAH composites.

The addition of TP filler increased the hardness and stiffness of the composites, thus lowering the elongation at break. The use of rigid filler inside ductile polymer matrix hindered the flow of polymer molecules past one another leading to less ductility of the composites. ${ }^{16}$ When load was applied, the brittle RHDPE/EVA/TP composites fractured completely within a short time compared to RHDPE/EVA blend which elongated longer due to the elastic characteristic of polymer. On the other hand, it can be observed that the addition of coupling agent and compatibiliser decreased the elongation at break of the composite. Among the treated composites, RHDPE/EVA/TP/CL-MAH composites exhibited the lowest elongation at break followed by RHDPE/EVA/TP/PE-g-MAH and RHDPE/EVA/TP ${ }_{\mathrm{MMA}}$ composites. Addition of compatibiliser increased the reinforcement strength in composites resulting in high rigidity or brittle composites, hence reducing the elongation at break value. ${ }^{17}$

Figure 3 shows the modulus of elasticity of RHDPE/EVA, RHDPE/EVA/TP,

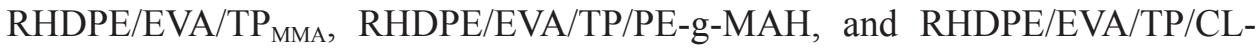
MAH composites. The modulus of elasticity of RHDPE/EVA blend was found to be the lowest compared to other filled composites. Meanwhile, RHDPE/EVA/ TP/CL-MAH exhibited the highest modulus of elasticity followed by RHDPE/ EVA/TP/PE-g-MAH, RHDPE/EVA/TP ${ }_{\text {MMA }}$ and uncompatibilised RHDPE/EVA/ 
TP composites. The addition of TP filler into the RHDPE/EVA/TP composites increased the modulus of elasticity. This can be explained by the rigid characteristic shown by TP filler. The addition of more rigid and non-soluble particles to polymer matrix will increase the composite stiffness. ${ }^{18,19}$ Besides, due to the incorporation of coupling agent and compatibiliser, the modulus of elasticity of the composites improved slightly. This may be due to the formation of bond or linkage introduced between filler and matrix, which promoted better dispersion of TP filler particles into the RHDPE/EVA matrix and good interfacial adhesion between the two different phases. ${ }^{20}$

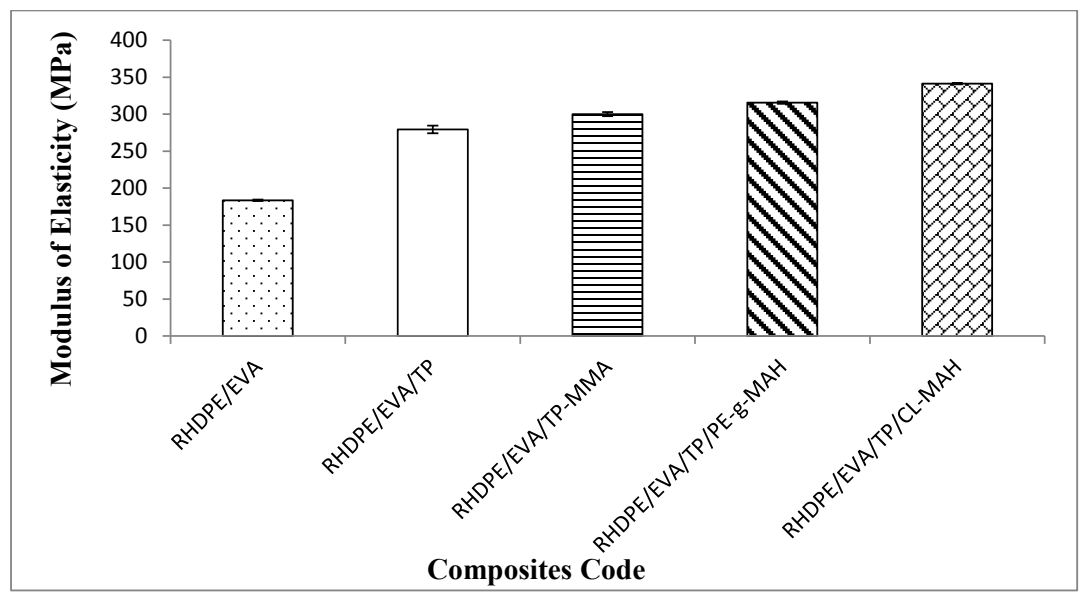

Figure 3: Modulus of elasticity of RHDPE/EVA, RHDPE/EVA/TP, RHDPE/EVA/TP MMA, $_{\text {, }}$ RHDPE/EVA/TP/PE-g-MAH, and RHDPE/EVA/TP/CL-MAH composites.

Both RHDPE/EVA/TP/PE-g-MAH and RHDPE/EVA/TP/CL-MAH composites exhibited higher modulus of elasticity value compared to the rest of the composites. Anhydride groups in the MAH can react with the hydroxyl groups of TP filler and lead to the formation of ester bond which improved the interfacial adhesion between polymer matrix and TP filler particle. ${ }^{21}$ The highest modulus of elasticity showed by both compatibilised composites is attributed to the improvement in interfacial adhesion within the composites as great stress transfer can be obtained from the compatibility of the matrix and reinforcing filler.

\subsection{Swelling Behaviour}

Figure 4 presents the percentage mass swell of RHDPE/EVA, RHDPE/EVA/TP, RHDPE/EVA/TP ${ }_{\text {MMA }}$, RHDPE/EVA/TP/PE-g-MAH, and RHDPE/EVA/TP/CL$\mathrm{MAH}$ composites. The results show that the filled RHDPE/EVA/TP composites 
exhibited lower percentage mass swell compared to neat RHDPE/EVA blend. The polar group of EVA was very reactive to the polar group of dichloromethane, thus higher dichloromethane uptake by the blend caused higher percentage of mass swell in neat RHDPE/EVA blend. Meanwhile, the addition of $25 \mathrm{phr}$ of TP filler reduced the percentage of polymer matrix in the composites ascribed to the lower absorption of dichloromethane by RHDPE/EVA/TP composites. Even though TP filler is natural filler with hydrophilicity characteristics, the results show that the hydrophilicity TP cannot be compared to the reactive reaction between polar groups in EVA and dichloromethane, hence RHDPE/EVA/TP composites had lower percentage mass swell than the neat RHDPE/EVA blend.

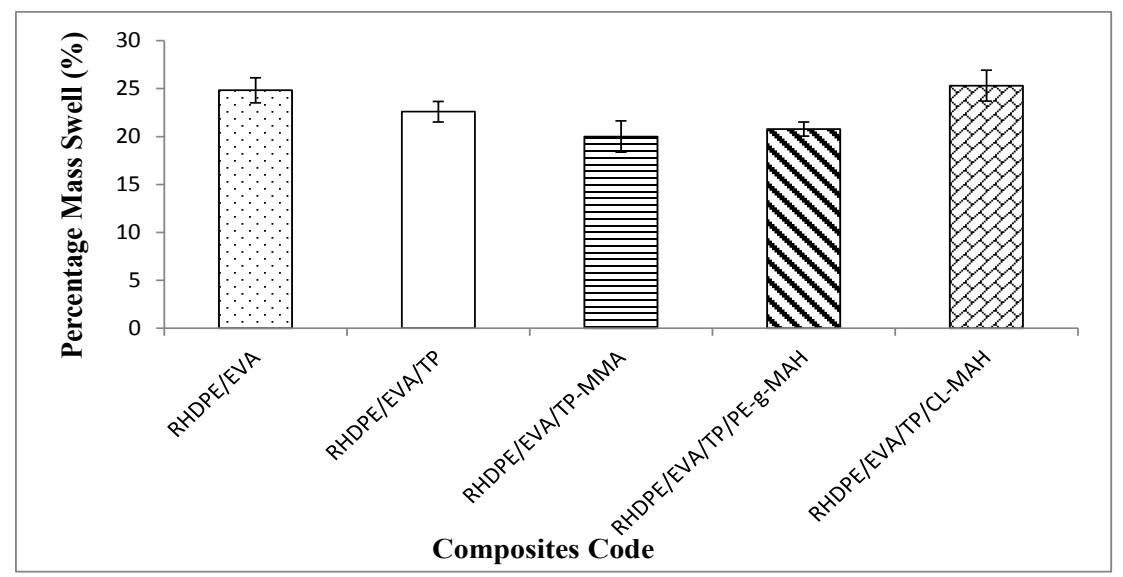

Figure 4: Percentage mass swell of RHDPE/EVA, RHDPE/EVA/TP, RHDPE/EVA/ $\mathrm{TP}_{\mathrm{MMA}}, \quad \mathrm{RHDPE} / \mathrm{EVA} / \mathrm{TP} / \mathrm{PE}-\mathrm{g}-\mathrm{MAH}$, and RHDPE/EVA/TP/CL-MAH composites.

The RHDPE/EVA/TP ${ }_{\mathrm{MMA}}$ composites exhibited the lowest percentage mass swell among all composites. The treatment of TP filler with MMA results in the removal of hemcellulose and lignin constituents contributed to improved chemical resistance properties. In addition, the reactions between acetyl groups $\left(\mathrm{CH}_{3} \mathrm{CO}\right)$ from MMA to hydroxyl groups $(\mathrm{OH})$ of TP filler decreased the hydrophobic nature of the filler leading to the reduction in dichloromethane intake and lower the percentage mass swell. 22

Meanwhile, the RHDPE/EVA/TP/PE-g-MAH composites exhibited the lowest percentage of mass swell after the RHDPE/EVA/TP ${ }_{\text {MMA }}$ composites. The anhydride groups in maleic anhydride reacted with the hydroxyl groups of TP filler causing reduction in the number of $\mathrm{OH}$ groups from the TP filler, hence reducing hydrophilicity of the composites. This will lead to lower absorption of 
dichloromethane, therefore decreasing the percentage mass swell of the composites. However, the addition of CL-MAH as compatibiliser in RHDPE/EVA/TP/CLMAH composite increased the percentage mass swell of the composite. This reason can be explained by the reactive reaction of methyl group in dichloromethane to the amide group of caprolactam. Overall intake of dichloromethane into RHDPE/ EVA/TP/CL-MAH composites include the reactive reaction of dichloromethane with caprolactam, hydrophilicity of TP and reaction between polar groups of EVA, and dichloromethane caused the percentage mass swell to increase greatly compared to the other composites.

\subsection{Scanning Electron Microscopy (SEM)}

The SEM micrographs of tensile fractured surfaces of RHDPE/EVA, RHDPE/ EVA/TP, RHDPE/EVA/TP ${ }_{\text {MMA }}$, RHDPE/EVA/TP/PE-g-MAh, and RHDPE/EVA/ TP/CL-MAH were shown in Figure 5. Figure 5(a) shows that the micrograph of tensile fracture surface of RHDPE/EVA blend had smooth surface with the stress induced pull out matrix, which can be related to the high elasticity characteristic of polymer matrix as reported in the elongation at break results. However, addition of TP filler to the rest of the composites changed the tensile fracture surfaces morphology to harder and rougher surfaces with presence of small voids, gaps and defects. The voids can be clearly seen especially in Figure 5(b) of uncompatibilised RHDPE/EVA/TP composites. This can be attributed to the poor wettability of filler to matrix which caused easy detachment when stress is applied. The treatment of TP with MMA improved interfacial adhesion of the composites thus better morphology of tensile fracture surface can be observed from Figure 5(c) with less voids.

In contrast to the uncompatibilised composites, the morphology of the tensile fractured surface of the compatibilised composites showed in Figure 5(d) and 5(e) displays normal fracture with preferable tearing line rather than voids due to less number of pulling out filler. This results suggested better interfacial adhesion formation between matrix and filler with indistinct interfacial bounds featured to the ester bond formed between the compatibiliser and the hydroxyl group of filler. These SEM features are in agreement with the tensile test results as reported in Figure 1. 


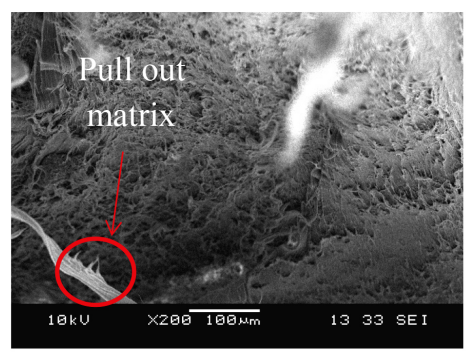

(a) RHDPE/EVA

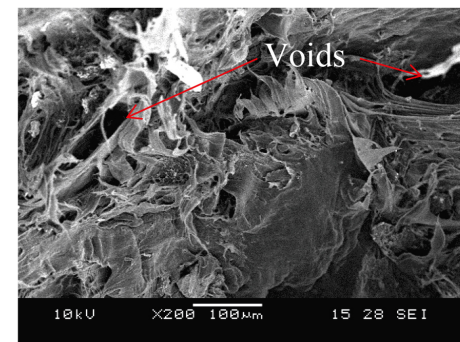

(b) RHDPE/EVA/TP-25

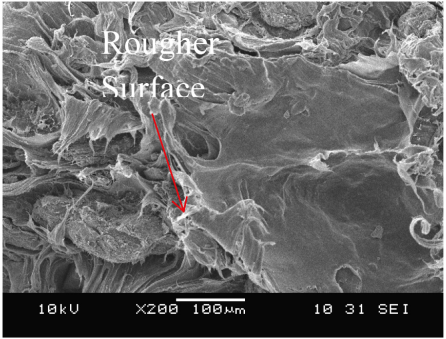

(d) RHDPE/EVA/TP-25/PE-g-MAH

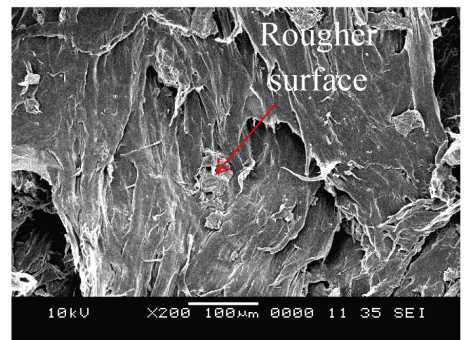

(c) RHDPE/EVA/TP MMA -25

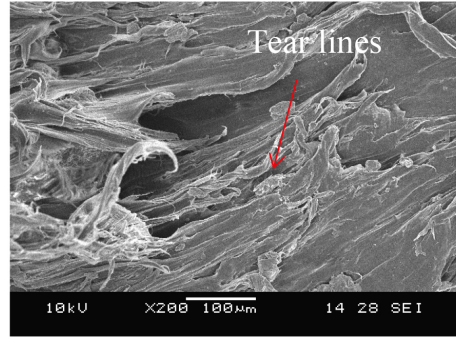

(e) RHDPE/EVA/TP-25/CL-MAH

Figure 5: SEM of RHDPE/EVA, RHDPE/EVA/TP, RHDPE/EVA/TPMMA, RHDPE/ EVA/TP/PE-g-MAH, and RHDPE/EVA/TP/CL-MAH composites.

\section{CONCLUSION}

In the study, RHDPE/EVA/TP composites were prepared with different modification techniques. The composites were tested and evaluated to study the effect of the modifications on their properties. The tensile study showed that presence of TP filler decreased the tensile strength and elongation at break of the composites, although it increased the modulus of elasticity. Besides, the treated and compatibilised RHDPE/EVA/TP composites were found to have higher tensile strength and modulus of elasticity while lowering elongation at break. Swelling test revealed that the addition of TP filler into the matrix reduced percentage mass swell of the 
composites and upon treatment and compatibilisation, the percentage mass swell reduced further except for RHDPE/EVA/TP/CL-MAH composites. Morphology observation showed that the modifications of the composites enhanced interfacial adhesion with rougher surface and less voids can be spotted on the micrographs.

\section{REFERENCES}

1. La Mantia, F. P. \& Morreale, M. (2011). Green composites: A brief review. Compos. A,42,579-588, https://doi.org/10.1016/j.compositesa.2011.01.017.

2. Ahmad, J. (2009). Machining of polymer composites. New York: Springer, https://doi.org/10.1007/978-0-387-68619-6.

3. Krishnaraj, V., Zitoune, R. \& Davim, J. P. (2013). Drilling of polymer-matrix composites. Berlin: Springer.

4. Cha, K. K. (2013). Composite materials: Science and engineering. New York: Springer.

5. Oza, S. et al. (2014). Effect of surface treatment stability of the hemp-PLA composites: Correlation of activation energy with thermal degradation. Compos. B, 67, 227-232.

6. Zhao, X., Li, R. K. Y. \& Bai, S. (2014). Mechanical properties of sisal fiber reinforced high density polyethylene composites: effect of fiber content, interfacial compatibilization, and manufacturing process. Compos. A, 65, 169-174.

7. Bindu, T. et al. (2008). Pollutant removal from domestic wastewater with Taro (Colocasia esculenta) planted in a subsurface flow system. Ecol. Eng., $33,68-82$.

8. Howeler, R. H. (1996). Cassava, starch and starch derivatives. Paper presented at the Proceedings of an International Symposium, Guangxi, China, 101.

9. Jandas, P. J., Mohanty, S. \& Nayak, S. K. (2013). Surface treated banana fiber reinforced poly (lactic acid) nanocomposites for disposable applications. $J$. Clean. Prod., 52, 392-401.

10. Abdelmouleh, M. et al. (2007). Short natural-fibre reinforced polyethylene and natural rubber composites: Effect of silane coupling agents and fibres loading. Compos. Sci. Technol., 67, 1627-1639.

11. Liu, H. et al. (2008). Compatibilizing and toughening bamboo flour-filled HDPE composites: Mechanical properties and morphologies. Compos. A, 39, 1891-1900.

12. Goodship, V. (Ed.). (2010). Management, recycling and reuse of waste composites. Cambridge: Woodhead Publishing. 
13. Noorunnisa Khanam, P. \& AlMaadeed, M. A. (2014). Improvement of ternary recycled polymer blend reinforced with date palm fibre. Mater. Des., 60, 532-539.

14. Mirabella, F. M. \& Bafna, A. (2002). Determination of the crystallinity of polyethylene/ $\alpha$-olefin compolymers by thermal analysis: Relationship of the heat of fusion of $100 \%$ polyethylene crystal and the density. J. Polym. Sci. $B, 40,1637-1643$.

15. Kabir, M. M. et al. (2012). Chemical treatments on plant-based natural fibre reinforced polymer composites: An overview. Compos. B, 43, 2883-2892.

16. Essabir, H. et al. (2016). Structural, mechanical and thermal properties of bio-based hybrid composites from waste coir residues: Fibers and shell particles. Mech. Mater., 93, 134-144.

17. Ndlovu, S.S., van Reenen, A. J. \& Luyt, A. S. (2013). LDPE-wood composites utilizing degrade LDPE as compatibilizer. Compos. A, 51, 80-88.

18. Granda, L. A. et al. (2016). Semichemical fibres of Leucaena collinsii reinforced polypropylene composites: Young's modulus analysis and fibre diameter effect on the stiffness. Compos. B, 92, 332-337.

19. Lopez, J. P. et al. (2012). Analysis of the tensile modulus of polypropylene composites reinforced with stone groundwood fibers. Bioresour., 7, 1310-1323.

20. Essabir, H. et al. (2013). Dynamic mechanical thermal behavior analysis of doum fibers reinforced polypropylene composites. Mater. Des., 15, 780-788.

21. Gao, H. et al. (2012). Grafting effects of polypropylene/polyethylene blends with maleic anhydride on the properties of the resulting wood-plastic composites. Compos. A, 43, 150-157.

22. Mishra, S. et al. (2003). Studies on mechanical performance of biofibre/ glass reinforced polyester hybrid composites. Compos. Sci. Technol., 63, $1377-1385$. 